\title{
Inference of SARS-CoV-2 spike-binding neutralizing antibody titers in sera from hospitalized COVID-19 patients by using commercial enzyme and chemiluminescent immunoassays
}

\author{
Arantxa Valdivia ${ }^{1} \cdot$ Ignacio Torres $^{1}$ - Víctor Latorre ${ }^{2}$ - Clara Francés-Gómez ${ }^{2}$ - Eliseo Albert ${ }^{1}$. \\ Roberto Gozalbo-Rovira ${ }^{3}$ - María Jesús Alcaraz ${ }^{1}$ - Javier Buesa ${ }^{1,3} \cdot$ Jesús Rodríguez-Díaz $^{3} \cdot$ Ron Geller $^{2}$. \\ David Navarro ${ }^{1,3}$ (D)
}

Received: 16 September 2020 / Accepted: 13 December 2020 / Published online: 6 January 2021

(C) The Author(s), under exclusive licence to Springer-Verlag GmbH, DE part of Springer Nature 2021

\begin{abstract}
Whether antibody levels measured by commercially available enzyme or chemiluminescent immunoassays targeting the SARSCoV-2 spike (S) protein can act as a proxy for serum neutralizing activity remains to be established for many of these assays. We evaluated the degree of correlation between neutralizing antibodies (NtAb) binding the SARS-CoV-2 spike (S) protein and SARS-CoV-2-S-IgG levels measured by four commercial immunoassays in sera drawn from hospitalized COVID-19 patients. Ninety sera from 51 hospitalized COVID-19 patients were tested by a pseudotyped virus neutralization assay, the LIAISON SARS-CoV-2 S1/S2 IgG, the Euroimmun SARS-CoV-2 IgG ELISA, the MAGLUMI 2019-nCoV IgG, and the COVID-19 ELISA IgG assays. Overall, the results obtained with the COVID-19 ELISA IgG test showed the highest agreement with the $\mathrm{NtAb}$ assay $(\kappa, 0.85 ; 95 \% \mathrm{CI}, 0.63-1)$. The most sensitive tests were the pseudotyped virus NtAb assay and the COVID-19 ELISA IgG assay ( $92.2 \%$ for both). Overall, the degree correlation between antibody titers resulting in $50 \%$ virus neutralization $\left(\mathrm{NtAb}_{50}\right)$ in the pseudotyped virus assay and SARS-CoV-2 IgG levels was strong for the Euroimmun SARS-CoV-2 IgG ELISA $\left(\mathrm{rho}=0.73\right.$ ) and moderate for the remaining assays (rho $=0.48$ to 0.59 ). The kinetic profile of serum $\mathrm{NtAb} \mathrm{b}_{50}$ titers could not be reliably predicted by any of the SARS-CoV-2 IgG immunoassays. The suitability of SARS-CoV-2-S-IgG commercial immunoassays for inferring neutralizing activity of sera from hospitalized COVID-19 patients varies widely across tests and is influenced by the time of sera collection after the onset of symptoms.
\end{abstract}

Keywords SARS-CoV-2 · COVID-19 · Neutralizing antibodies · Enzyme-linked immunosorbent assay · Chemiluminescent immunoassays

\section{Introduction}

Severe acute respiratory syndrome coronavirus 2 (SARS-CoV2), a prototypical sarbecovirus, causes coronavirus disease 2019 (COVID-19) and is associated with significant morbidity and mortality $[1,2]$. SARS-CoV-2 neutralizing antibodies

David Navarro

david.navarro@uv.es

1 Microbiology Service, Clinic University Hospital, INCLIVA Health Research Institute, Valencia, Spain

2 Institute for Integrative Systems Biology (I2SysBio), Universitat de Valencia-CSIC, Valencia, Spain

3 Department of Microbiology, School of Medicine, University of Valencia, Av. Blasco Ibáñez 17, 46010 Valencia, Spain
(NtAb) presumably play a pivotal role in preventing infection and may promote virus clearance [3, 4]. In support of these assumptions, passive transfer of two mAbs blocking SARS$\mathrm{CoV}-2$ interaction with angiotensin-converting enzyme II receptor as monotherapy protected rhesus macaques from infection [5]. Moreover, transfusion of plasma from immune individuals with high NtAb titers seemed to be associated with improved clinical outcomes in critically ill COVID-19 patients $[6,7]$. Virus neutralization assays, either using live native SARS-CoV-2 virus, engineered SARS-CoV-2 pseudotyped viruses, or replication-competent SARS-CoV-2 chimeric viruses are cumbersome, require specialized facilities, and are time consuming [8-10]. A large number of enzyme-linked (ELISA) or chemiluminescent immunoassays (CLIA) detecting antibodies that bind SARS-CoV-2 structural proteins have been commercialized [11]. Whether antibody levels measured by 
these serological assays can be used as a proxy for serum neutralizing activity is a relevant issue, which has been dealt with in several peer-reviewed or preprint studies [12-20], but demands further investigations. Here, we focused on evaluating the degree of correlation between NtAb binding the SARS-CoV-2 S protein, which is known to elicit the most potent antibodies for virus neutralization $[21,22]$ and SARS-CoV-2 IgG levels measured by four commercially available semiquantitative immunoassays targeting the $\mathrm{S}$ protein in sera drawn from hospitalized COVID-19 patients.

\section{Material and methods}

\section{Serum specimens and patients}

In this retrospective study, a total of 90 sera from 51 nonconsecutive patients with laboratory-confirmed SARS-CoV2 infection by RT-PCR that were admitted to Hospital Clínico Universitario of Valencia between March 5 and April 30, 2020 , were included [23, 24]. The only patients' inclusion criterium was the availability of leftover sera obtained for routine SARS-CoV-2 serological testing. Sera had been cryopreserved $\left(-20^{\circ} \mathrm{C}\right)$ for a maximum of one month since collection, and never thawed prior to performing the analyses reported herein. All serological assays were performed within one week as described below. The demographic, clinical, and laboratory data of these patients are displayed in Table 1 . Forty-one sera were obtained within the first two weeks (< day 15) after the onset of symptoms, at a median of 11 days (range, 5-14 days), and 49 afterward ( $\geq 15$ days, at a median of 23 days; range, 15-41 days). Sequential specimens were available from 20 out of the 51 patients (median 3 specimens per patient; range 2 to 6 ). A total of 20 pre-pandemic sera from healthy individuals collected within 2019, of which 10 belonged to patients with prior endemic coronavirus infections (HCoV-229E, $n=8$; HCoV NL63, $n=1$; HCoVHKU, $n=1$ ), were included as controls. This study was approved by the Research Ethics Committee of Hospital Clínico Universitario INCLIVA (March 2020).

\section{SARS-CoV-2 neutralizing antibody assay}

A green fluorescent protein (GFP) reporter-based pseudotyped virus neutralization assay using a non-replicative vesicular stomatitis virus (VSV lacking the G protein) backbone coated with the SARS-CoV-2 spike (S) protein was used for neutralization assays on Vero cells, as previously described [24]. Briefly, sera were heat-inactivated for $30 \mathrm{~min}$ at $56{ }^{\circ} \mathrm{C}$ then brought to an initial 10-fold dilution, followed by four 4 -fold dilutions in duplicate. Each dilution was mixed with an equal volume containing 1250 plaque-forming units of the VSV-S virus and incubated at $37^{\circ} \mathrm{C}$ for $1 \mathrm{~h}$. Subsequently, the mixture was added
Table 1 Demographic, clinical, and laboratory characteristics of patients with COVID-19

\begin{tabular}{ll}
\hline Parameter & Patients \\
\hline Sex: male/female; no. (\%) & $32(63) / 19(37)$ \\
Age; median (range) & $53(21-77)$ \\
Days of hospitalization; median (range) & $17(2-67)$ \\
Comorbidities; no. $(\%)$ & $35(69)$ \\
Number of comorbidities; median (range) & $1(0-5)$ \\
Arterial hypertension & $23(45)$ \\
Chronic renal disease & $2(4)$ \\
Diabetes mellitus & $12(24)$ \\
Dyslipidemia & $16(31)$ \\
Ischemic cardiovascular disease & $4(8)$ \\
Myocardial infarction & $2(4)$ \\
Pulmonary disease & $7(14)$ \\
Tumor & $3(6)$ \\
Laboratory findings; median (range) & \\
CRP (in mg/L) & $44(0.8-273)$ \\
Ferritin (ng/mL) & $674(2.5-2986)$ \\
Dimer-D (ng/mL) & $903(91-5445)$ \\
Lactose dehydrogenase $(\mathrm{U} / \mathrm{L})$ & $666(357-1328)$ \\
Interleukin-6 (pg/mL) & $1012(4.6-5000)$ \\
Total lymphocyte count $\left(* 10^{9} / \mathrm{L}\right)$ & $1.15(0.17-3.98)$ \\
\hline
\end{tabular}

${ }^{a}$ Measurements in sera used for serological analyses reported in the current study

to Vero cells and incubated for $18 \mathrm{~h}$, after which GFP expression was measured using a live cell microscope system (IncuCyteS3; Sartorius). All sera which did not reduce viral replication by $50 \%$ at $1 / 20$ dilution were considered nonneutralizing and were arbitrarily assigned a value of $1 / 10$. All sera that did not result in $>70 \%$ recovery of GFP signal at the highest antibody dilution were retested using 5 -fold dilutions ranging between 100- and 12,500-fold. Finally, the antibody dilution resulting in $50 \%$ virus neutralization $\left(\mathrm{NtAb}_{50}\right)$ was calculated using the drc package (version 3.0-1) in $\mathrm{R}$ via a 2 parameter logistic regression model (LL.2 model). In a previous study, by testing 90 sera from.

\section{Commercial SARS-CoV-2 IgG immunoassays}

Four commercially available semiquantitative immunoassays were used in the current study. Performance and interpretation of results were done in accordance with the respective manufacturer's instructions. The LIAISON SARS-CoV-2 S1/S2 IgG chemiluminescent assay (DiaSorin S.p.A., Saluggia, Italy) detects IgG antibodies directed against a recombinant $\mathrm{S}$ protein $(\mathrm{S} 1 / \mathrm{S} 2)$. Samples displaying $<12.0 \mathrm{AU} / \mathrm{mL}$ are considered negative, those ranging between 12.0 and $15.0 \mathrm{AU} /$ $\mathrm{mL}$ are undetermined, and those $>15 \mathrm{AU} / \mathrm{mL}$ are deemed as 
positive. The Euroimmun SARS-CoV-2 IgG ELISA (Euroimmun, Lübeck, Germany) uses a recombinant S1 domain of the $\mathrm{S}$ protein as a target. Results are expressed as a ratio, calculated by dividing the optical densities of the sample by those of an internal calibrator provided with the test kit. The cut-off index (COI) for samples to be considered positive was $\geq 1.1$ and inconclusive from 0.8 and 1.09 . The MAGLUMI 2019-nCoV IgG is an indirect CLIA for assessment of IgG antibodies against SARS-CoV-2 S and nucleocapsid $(\mathrm{N})$ proteins on the fully automated MAGLUMI analyzers (SNIBE - Shenzhen New Industries Biomedical Engineering Co., Ltd., Shenzhen, China). A test result $\geq$ $1.10 \mathrm{AU} / \mathrm{mL}$ is considered positive. The COVID-19 ELISA IgG (Vircell Spain S.L.U., Granada, Spain) is an enzyme immunoassay that detects IgGs targeting the $\mathrm{S} 1$ and $\mathrm{N}$ proteins. Sera displaying antibody indices $(\mathrm{AI})<1.4$ are considered negative, those between $1.4<1.6$ inconclusive, and those $>$ 1.6 positive. For all the assays, inconclusive results were considered as positives for analysis purposes.

\section{Definitions}

Here, $\mathrm{NtAb}$ titers $\geq 1 / 160$ were considered high as this is the minimum $\mathrm{NtAb}_{50}$ titer of plasma from COVID-19 convalescent individuals recommended by the FDA for therapeutic use [25]. Trajectories of antibody titers/levels were categorized as ascendant, descendant, fluctuating, or constant. To this end, variations of antibody levels $>10 \%$ across sequential specimens were deemed to be relevant, as the intra-run coefficient of variation was below this figure for all the immunoassays (all samples from a given individual were assayed in the same run).

\section{Statistical methods}

Test performances were evaluated for their sensitivity with the associated 95\% confidence interval (CI). Cohen's kappa $(\kappa)$ statistic was used to evaluate the qualitative agreement between immunoassays. Spearman's rank test was used to assess the correlation between continuous variables using the entire dataset. To identify the optimal SARS-CoV-2 IgG levels measured by commercial immunoassays predicting $\mathrm{NtAb}_{50}$ titers $\geq 1 / 160$, receiver operating characteristic (ROC) curve analysis was performed. Two-sided exact $P$ values are reported, and a $P$ value $<0.05$ is considered statistically significant. The analyses were performed using SPSS version 20.0 (SPSS, Chicago, IL, USA). Kinetics of antibody titers/levels were categorized as ascendant (an increase of antibody levels > $10 \%$ compared to previous sampling point), descendant (any decrease), fluctuating, or constant.

\section{Results}

\section{Patients characteristics}

All 51 patients presented with pneumonia and imaging or laboratory findings compatible with COVID-19 and were hospitalized in either the pneumology ward $(n=27)$ or the intensive care unit (ICU; $n=24$ ). As shown in Table 1, most patients $(69 \%)$ had one or more comorbidities and displayed high serum levels of several pro-inflammatory biomarkers at the time of serological testing. Four ICU patients eventually died.

\section{Specificity of NtAb and SARS-CoV-2 lgG immunoassays}

Out of the 20 control sera, none returned positive results by any of the immunoassays used in the study. Thus, the specificity of CLIA and the NtAb assays was $100 \%$ (95\% CI, 83.9-100\%).

Table 2 Performance of an antibody neutralization method using a reporter-based pseudotyped virus (vesicular stomatitis virus pseudotyped with the SARS-CoV-2 spike protein) and four commercial SARS-CoV-2 IgG immunoassays for the diagnosis of COVID-19

\begin{tabular}{|c|c|c|c|c|c|}
\hline \multirow{2}{*}{$\begin{array}{l}\text { Qualitative results/time of sampling } \\
\text { after the onset of symptoms }{ }^{\mathrm{a}}\end{array}$} & \multicolumn{5}{|l|}{ Antibody assay } \\
\hline & $\begin{array}{l}\text { GFP-VSV-SARS-CoV-2 S } \\
\text { pseudotype NtAb test }\end{array}$ & $\begin{array}{l}\text { Euroimmun SARS- } \\
\text { CoV-2 IgG ELISA }\end{array}$ & $\begin{array}{l}\text { LIAISON SARS- } \\
\text { CoV-2 S1/S2 IgG }\end{array}$ & $\begin{array}{l}\text { MAGLUMI } \\
\text { 2019-nCoV IgG }\end{array}$ & $\begin{array}{l}\text { COVID-19 } \\
\text { ELISA IgG }\end{array}$ \\
\hline Positive (all sera) & 83 & 76 & 75 & 77 & 83 \\
\hline Negative (all sera) & 7 & 14 & 15 & 13 & 7 \\
\hline Positive $/<15$ days & 37 & 31 & 30 & 31 & 37 \\
\hline Negative $/<15$ days & 4 & 10 & 11 & 10 & 4 \\
\hline Positive $/ \geq 15$ days & 46 & 45 & 45 & 46 & 46 \\
\hline Negative $/ \geq 15$ days & 3 & 4 & 4 & 3 & 3 \\
\hline
\end{tabular}

${ }^{\text {a }}$ A total of 90 sera were included, of which 41 were collected $<15$ days after the onset of symptoms and 49 afterwards $(\geq 15$ days $)$ 
Table 3 Agreement between the results of a reporter-based pseudotyped virus antibody neutralization method (vesicular stomatitis virus pseudotyped with the SARS-CoV-2 spike protein) and four commercial SARS-CoV-2 IgG immunoassays

\begin{tabular}{|c|c|c|c|c|}
\hline \multirow{2}{*}{$\begin{array}{l}\text { Paired results (NtAb } \\
\text { assay/commercial im- } \\
\text { munoassay) }\end{array}$} & \multicolumn{4}{|l|}{ Commercial immunoassay } \\
\hline & $\begin{array}{l}\text { MAGLUMI } 2019-\text {-nCoV } \\
\text { IgG: all sera/sera }<15 \text { days/ } \\
\text { sera } \geq 15 \text { days }\end{array}$ & $\begin{array}{l}\text { LIAISON SARS-CoV-2 S1/S2 } \\
\text { IgG: all sera/sera }<15 \text { days/sera } \\
\geq 15 \text { days }\end{array}$ & $\begin{array}{l}\text { Euroimmun SARS-CoV-2 IgG } \\
\text { ELISA: all sera/sera }<15 \text { days/ } \\
\text { sera } \geq 15 \text { days }\end{array}$ & $\begin{array}{l}\text { COVID-19 ELISA IgG: } \\
\text { all sera/sera }<15 \text { days/se- } \\
\text { ra } \geq 15 \text { days }\end{array}$ \\
\hline Positive/positive & $75 / 30 / 45$ & $74 / 29 / 45$ & $75 / 30 / 45$ & $82 / 36 / 46$ \\
\hline Negative/negative & $5 / 3 / 2$ & $6 / 3 / 3$ & $6 / 3 / 3$ & $6 / 3 / 3$ \\
\hline Positive/negative & $8 / 7 / 1$ & $9 / 8 / 1$ & $8 / 7 / 1$ & $1 / 1 / 0$ \\
\hline Negative/positive & $2 / 1 / 1$ & $1 / 1 / 0$ & $1 / 1 / 0$ & $1 / 1 / 0$ \\
\hline
\end{tabular}

$N t A b$, neutralizing antibodies

A total of 90 sera were included, of which 41 were collected $<15$ days after the onset of symptoms and 49 afterward $(\geq 15$ days $)$

\section{Agreement between NtAb and SARS-CoV-2 IgG im- munoassays results}

Qualitative results returned by immunoassays were evaluated either considering the entire dataset or grouping sera according to the time of sampling after the onset of symptoms ( $<15$ days or $\geq 15$ days) (Table 2). As shown in Table 3, overall, results provided by the COVID-19 ELISA IgG test best matched those obtained with the $\mathrm{NtAb}$ assay $(\kappa, 0.84 ; 95 \% \mathrm{CI}, 0.63-1)$, followed by those of the Euroimmun SARS-CoV-2 IgG ELISA $(\kappa, 0.52 ; 0.52 ; 95 \% \mathrm{CI}, 0.22-0.81)$, LIAISON SARSCoV-2 S1/S2 IgG $(\kappa, 0.5 ; 95 \%$ CI, 0.2-0.78), and MAGLUMI 2019-nCoV IgG (0.4; 95\% CI, 0.2-0.77). The same trend was observed when sera collected either $<15$ days or $\geq 15$ days after the onset of symptoms were analyzed separately. Notably, the concordance between results returned by the $\mathrm{NtAb}$ assay and the COVID-19 ELISA IgG was $100 \%$ for sera obtained at $\geq$ 15 days following symptom onset.

\section{The sensitivity of NtAb and SARS-CoV-2 lgG immunoassays}

Overall, the most sensitive tests were the GFP reporter-based pseudotyped virus neutralization assay and the COVID-19
ELISA IgG, followed by the MAGLUMI 2019-nCoV IgG, the Euroimmun SARS-CoV-2 IgG ELISA, and the LIAISON SARS-CoV-2 S1/S2 IgG (Table 4). Differences in sensitivity were more apparent when sera were collected early after the onset of symptoms ( $<15$ days) were analyzed independently, and these tended to decrease in sera obtained at a later time point (Table 4).

\section{Correlation between $\mathrm{NtAb}_{50}$ titers and IgG levels measured by SARS-CoV-2 IgG immunoassays}

$\mathrm{NtAb}_{50}$ titers ranged from $\leq 1 / 20$ (undetectable) to $1 / 12,500$. As shown in Fig. 1, overall, the correlation between $\mathrm{NtAb}_{50}$ titers and SARS-CoV-2 IgG levels, as returned by the corresponding immunoassay, was strong for the Euroimmun SARS-CoV-2 IgG ELISA $(\mathrm{rho}=0.73)$ and moderate $($ rho $=$ 0.48 to 0.59 ) for the remaining platforms. In all instances, correlations were positive and statistically significant. The degree of correlation between $\mathrm{NtAb}_{50}$ titers and SARS-CoV-2 IgG levels was substantially better for sera collected within the first two weeks after the onset of symptoms (rho $=0.54-0.80)$ than for those obtained afterward (rho $=0.30-0.52$ ), irrespective of the commercial immunoassay employed.

Table 4 Clinical sensitivity of an antibody neutralization method using a reporter-based pseudotyped virus (vesicular stomatitis virus pseudotyped with the SARS-CoV-2 spike protein) and four commercial SARS-CoV-2 IgG immunoassays for the diagnosis of COVID-19

\begin{tabular}{|c|c|c|c|c|c|}
\hline \multirow[t]{2}{*}{ Sera included in the analyses } & \multicolumn{5}{|c|}{$\%$ sensitivity of the immunoassay $(95 \% \mathrm{CI})$} \\
\hline & $\begin{array}{l}\text { GFP-VSV-SARS-CoV-2 S } \\
\text { pseudotype NtAb test }\end{array}$ & $\begin{array}{l}\text { Euroimmun SARS- } \\
\text { CoV-2 IgG ELISA }\end{array}$ & $\begin{array}{l}\text { LIAISON SARS- } \\
\text { CoV-2 S1/S2 IgG }\end{array}$ & $\begin{array}{l}\text { MAGLUMI } \\
\text { 2019-nCoV IgG }\end{array}$ & $\begin{array}{l}\text { COVID-19 } \\
\text { ELISA IgG }\end{array}$ \\
\hline All sera ${ }^{a}$ & $92.2(86.7-97.8)$ & $84.4(77.0-91.9)$ & $83.3(75.6-91.0)$ & $85.6(78.3-92.8)$ & $\begin{array}{l}92.2 \\
\quad(86.7-97.8)\end{array}$ \\
\hline $\begin{array}{l}\text { Sera collected }<15 \text { days after the } \\
\text { onset of symptoms }{ }^{\mathrm{a}}\end{array}$ & $90.2(77.5-96.1)$ & $75.6(60.7-86.2)$ & $73.2(58.1-84,3)$ & $75.6(60.7-86.2)$ & $\begin{array}{l}90.2 \\
\quad(77.5-96.1)\end{array}$ \\
\hline $\begin{array}{l}\text { Sera collected } \geq 15 \text { days since } \\
\text { the onset of symptoms }{ }^{\mathrm{a}}\end{array}$ & $93.9(83.5-97.9)$ & $91.8(88.8-96.8)$ & $91.8(88,8-96.8)$ & $93.9(83,5-97.9)$ & $\begin{array}{l}93.9 \\
\quad(83.5-97.9)\end{array}$ \\
\hline
\end{tabular}

${ }^{\text {a }}$ A total of 90 sera were included, of which 41 were collected $<15$ days after the onset of symptoms and 49 afterwards $(\geq 15$ days $)$ 
Fig. 1 Correlation between $\mathrm{NtAb}_{50}$ titers measured by a SARS-CoV-2-S pseudotyped virus neutralization assay and $\mathrm{IgG}$ levels measured by commercial SARS-CoV-2 IgG immunoassays in all sera (a), in sera obtained within the first two weeks after the onset of symptoms $(<15$ days; b), and in sera collected afterward ( $\geq 15$ days; $\mathbf{c})$. For (a),

Rho and $P$ values were as follows: Euroimmun SARS-CoV-2 IgG , 0.73 and $\mathrm{P}<0.001$; MAGLUMI 2019-nCoV IgG, 0.48 and $\mathrm{P}<0.001$; LIAISON SARS-CoV$2 \mathrm{~S} 1 / \mathrm{S} 2 \mathrm{IgG}, 0.52$ and $\mathrm{P}<0.001$. COVID-19 ELISA IgG, 054 and $\mathrm{P}<0.001$. For (b) Rho and $\mathrm{P}$ values were as follows: 0.80 and $\mathrm{P}<0.001 ; 0.54$ and $\mathrm{P}<0.001 ; 0.68$ and $\mathrm{P}<0.001 ; 0.63$ and $\mathrm{P}<0.001$, respectively. For $(\mathbf{c})$ Rho and $P$ values were as follows: 0.55 and $\mathrm{P}<0.001 ; 0.30$ and $\mathrm{P}<0.03 ; 0.32$ and $\mathrm{P}=0.02 ; 0.39$ and $\mathrm{P}=0.005$, respectively
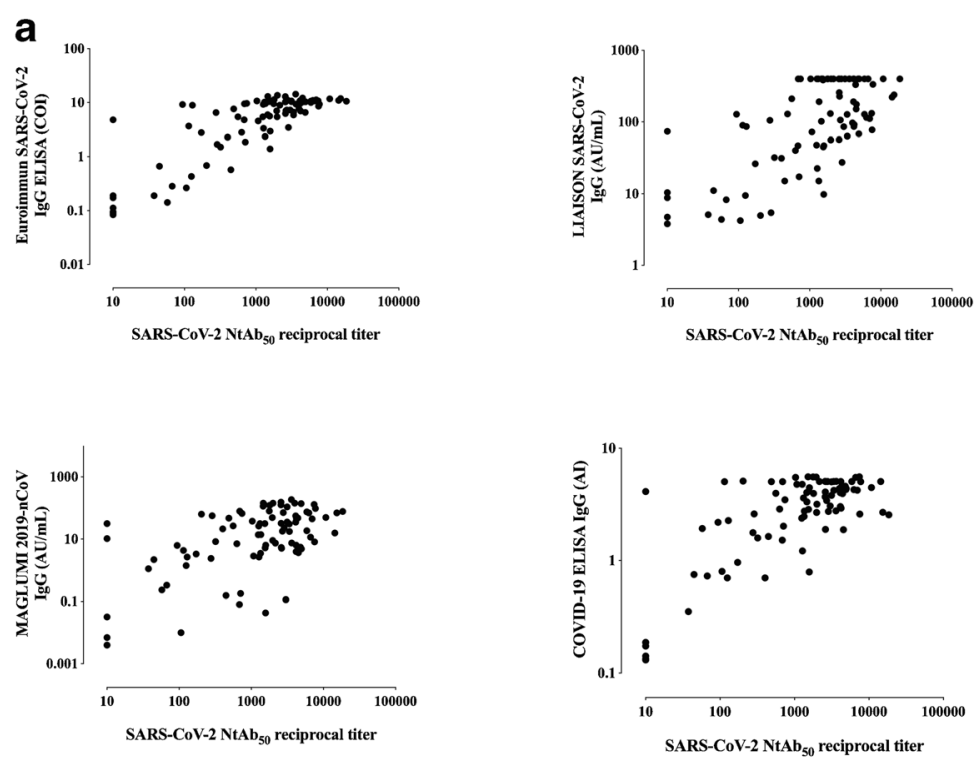

b
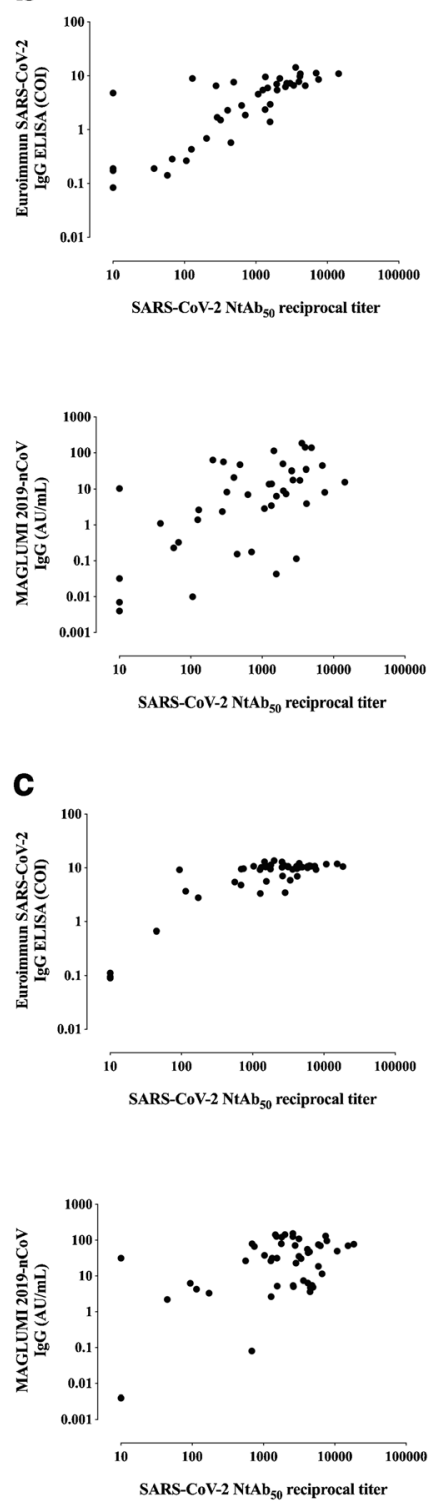
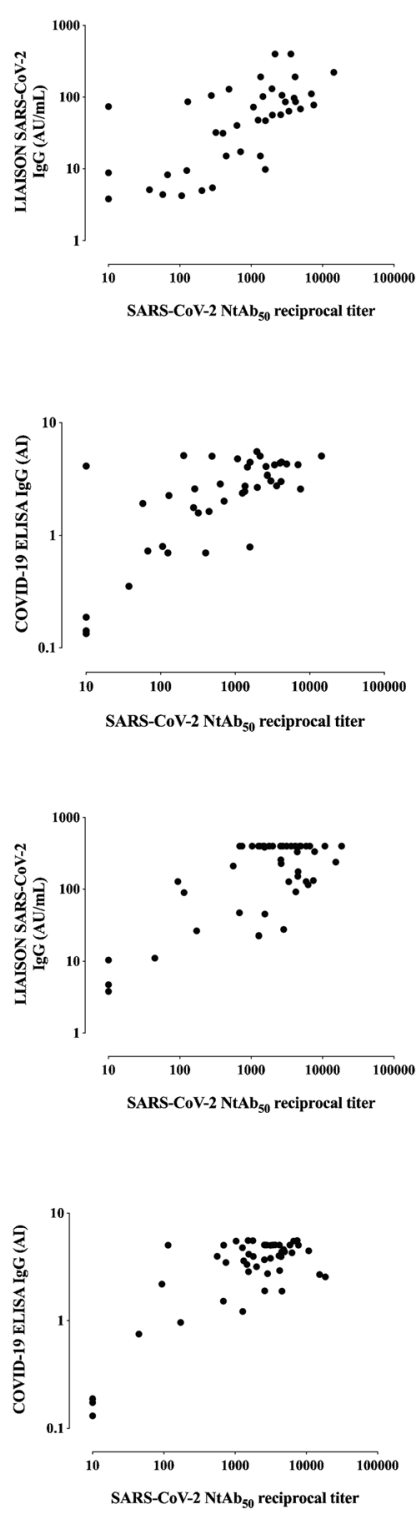


\section{Inference of high $\mathrm{NtAb}_{50}$ titers by using SARS-CoV-2 IgG immunoassays}

Seventy-four out of 90 sera displayed high $\mathrm{NtAb}_{50}$ titers $(\geq 1$ / 160 ). ROC analysis was performed to determine the $\operatorname{IgG}$ levels measured by commercial immunoassays that predict $\mathrm{NtAb}_{50}$ titers of such a magnitude (Fig. 2). Specificity was prioritized at the expense of sensitivity for threshold selection. The data are shown in Table 5. The best combination of specificity, sensitivity, and predictive values was achieved by the LIAISON SARS-CoV-2 S1/S2 IgG threshold, with minimal differences across the remaining platforms.

\section{Longitudinal follow-up of $\mathrm{NtAb}_{50}$ titers and SARS- CoV-2 IgG levels measured by immunoassays}

We selected patients $(n=11)$ with 3 or more sera available for kinetic studies. Kinetics of $\mathrm{NtAb}_{50}$ titers and SARS-CoV-2 IgG levels determined by commercial immunoassays varied notably across patients and were dependent on the immunoassay considered. Concordance between trajectories of $\mathrm{NtAb}_{50}$ titers and SARS-CoV-2 IgG levels was highest when using the COVID-19 ELISA IgG (6 out of 11 patients) assay, followed by MAGLUMI 2019-nCoV IgG (5 out of 11), and LIAISON SARS-CoV-2 S1/S2 IgG and Euroimmun IgG (both 3 out of 11) assays. Representative cases of concordant and discordant trajectories are depicted in Fig. 3.

\section{Discussion}

A major role in preventing SARS-CoV-2 infection and blunting virus spread in COVID-19 patients is predicted for $\mathrm{NtAb}$ [3-5]. Quantitation of serum NtAb titers in plasma from convalescent COVID-19 patients is recommended for optimal selection of specimens for passive transfer therapies; the FDA recommends the use of plasma with $\mathrm{NtAb}_{50}$ levels $\geq 1 / 160$ [22]. NtAb assays, either using SARS-CoV-2 strains, pseudotyped viruses, or chimeric viruses are technically demanding, require specialized facilities (biosafety level 3 for live SARS-CoV-2 or level 2 for the pseudotyped viruses), and cannot be implemented in routine practice. Thus, it is of interest to find alternative methods to obtain reliable information regarding the neutralizing activity of sera that are simple, fast, high-throughput assays, and commercially available. Here, we compared the performance of a GFP reporterbased pseudotyped virus neutralization assay (VSV-SARSCoV-2 S) and four commercial immunoassays also targeting the SARS-CoV-2 S protein, which in our experience displayed a specificity of $100 \%$, for the diagnosis of COVID-19 and assessed the extent to which NtAb $\mathrm{N}_{50}$ titers and SARS-CoV-2 IgG levels measured by these assays correlate. In our experience, all immunoassays displayed a specificity of $100 \%$. We chose to include two assays targeting the SARS-CoV-2 $\mathrm{N}$ protein in addition to the $\mathrm{S}$ protein (MAGLUMI 2019-nCoV IgG and the COVID-19 ELISA $\mathrm{IgG}$ ) to determine whether the combined use of both antigens would impact on the degree of correlation between SARSCoV-2 IgG levels and NtAb50 titers measured by a NtAb assay targeting exclusively the $\mathrm{S}$ protein. Prior studies assessing this relationship have been published for the Euroimmun SARS-CoV-2 IgG ELISA and LIAISON SARS-CoV-2 S1/S2 IgG [12, 13, 15, 18-20], but not, to the best of our knowledge, for the MAGLUMI 2019-nCoV IgG and COVID-19 ELISA IgG assays. It must be highlighted that antibody titers measured by the NtAb assay used in the current study strongly correlate with those quantitated by assays using wild-type SARS-CoV-2 [26].

Here, the overall agreement between qualitative (positive/ negative) results returned by the NtAb assay and the four commercially available immunoassays was fairly good, ranging from $97 \%$ for the COVID-19 ELISA IgG assay to $88 \%$ for LIAISON SARS-CoV-2 S1/S2 IgG and MAGLUMI 2019$\mathrm{nCoV}$ IgG assays. Concordance across results was better for sera obtained at late times after the onset of symptoms $(\geq$ 15 days), likely reflecting the existence of differences in the kinetics of NtAb and SARS-CoV-2 IgG levels measured by commercial immunoassays early after infection. In line with this finding, the COVID-19 ELISA IgG performed comparably to the NtAb assay in terms of overall sensitivity (92.2\%),
Table 5 SARS-CoV-2-S-IgG threshold levels measured by four commercial immunoassays for predicting neutralizing antibody titers $\geq$ $1 / 160$ measured by a reporter-based pseudotyped virus antibody neutralization method (vesicular stomatitis virus pseudotyped with the SARS-CoV-2 spike protein)

\begin{tabular}{llllll}
\hline Immunoassay & Threshold & Specificity (CI, 95\%) & Sensitivity (CI, 95\%) & $\begin{array}{l}\text { Positive predictive } \\
\text { value (CI, 95\%) }\end{array}$ & $\begin{array}{l}\text { Negative predictive } \\
\text { value (CI, 95\%) }\end{array}$ \\
\hline Euroimmun SARS-CoV-2 IgG ELISA & 8.9 COI & $93.8(81.5-100)$ & $55.4(44.1-66.7)$ & $97.6(87.7-99.6)$ & $31.2(19.9-45.3)$ \\
LIAISON SARS-CoV-2 S1/S2 IgG & $90.6 \mathrm{AU}$ & $93.8(81.5-100)$ & $67.6(56.9-78.2)$ & $98.1(89.7-99.7)$ & $38.5(24.9-54.1)$ \\
MAGLUMI 2019-nCoV IgG & $10.9 \mathrm{AU}$ & $93.8(81.5-100)$ & $64.9(54.0-75.7)$ & $98.0(89.3-99.6)$ & $36.6(23.6-51.9)$ \\
COVID-19 ELISA IgG & $4.1 \mathrm{AI}$ & $93.8(81.5-100)$ & $47.3(35.9-58.7)$ & $97.2(85.8-99.5)$ & $27.8(17.6-40.9)$ \\
\hline
\end{tabular}


Fig. 2 ROC curve analysis for establishing the optimal SARSCoV-2 IgG threshold levels that predict the presence of high $\mathrm{NtAb}_{50}$ titers $(\geq 1 / 160)$ in hospitalized patients with COVID-19 for the Euroimmun SARS-CoV-2 IgG ELISA (a), LIAISON SARSCoV-2 S1/S2 IgG assay (b), MAGLUMI 2019-nCoV IgG (c), and COVID-19 ELISA IgG (d) assays
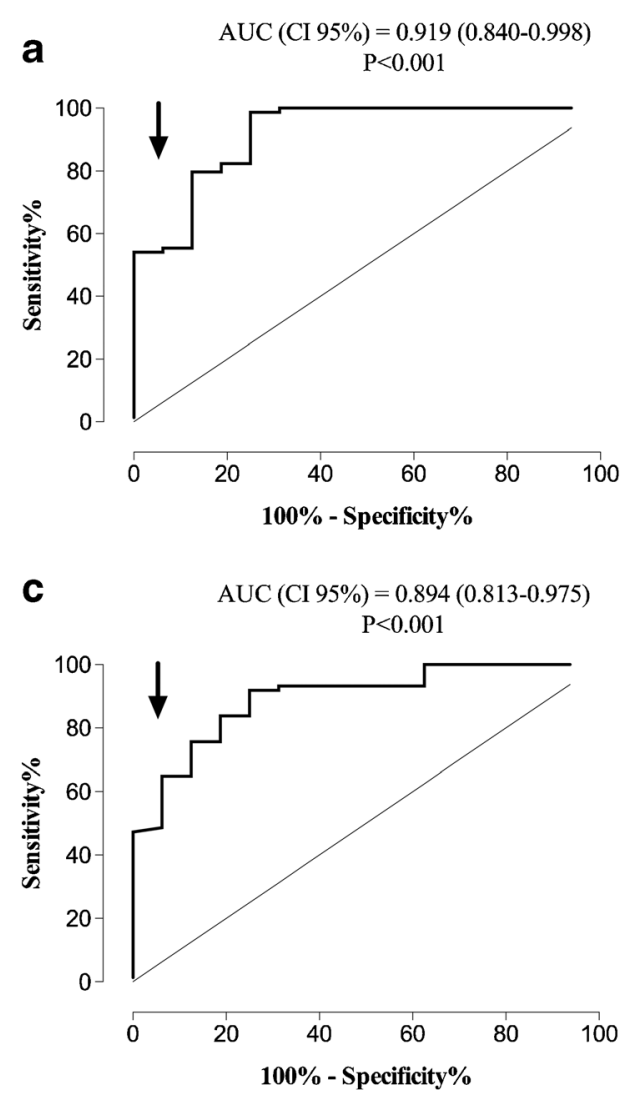
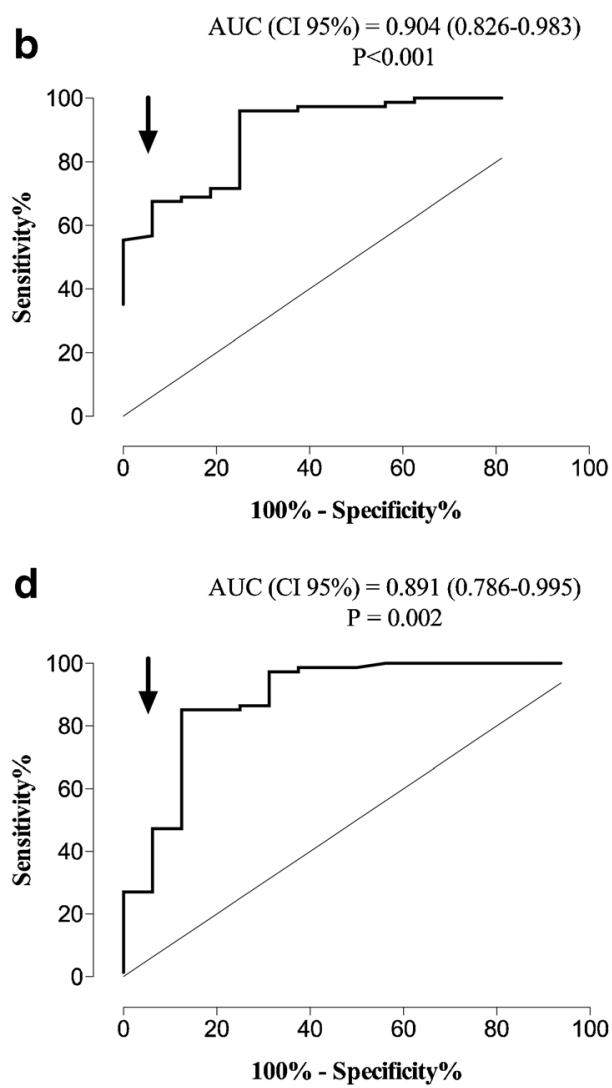

ranking first across the evaluated commercial immunoassays. As previously reported, the sensitivity of all immunoassays increased after the second week following the onset of symptoms $[12,13,15,16,18-20]$. The overall degree of correlation between $\mathrm{NtAb}_{50}$ antibody titers and SARS-CoV-2 IgG levels was strong for the Euroimmun IgG assay but low to moderate for the other commercial immunoassays. The fact that the Euroimmun $\operatorname{IgG}$ assay detects antibodies against S1, which contains the RBD domain and concentrates immunodominant epitopes eliciting high-affinity $\mathrm{NtAb}$ antibodies [3, 5, 21, 22], may account for this finding. IgG antibodies lacking neutralizing activity and recognizing epitopes within $\mathrm{S} 2$ and N proteins (additional targets in the remaining immunoassays) may compete with those binding S1, thus decreasing the degree of correlation. Interestingly, in all cases, correlations were better for sera collected early after the onset of symptoms than for those obtained at later times; in line with this, NtAb trajectory could not be inferred in a large fraction of patients by sequentially monitoring SARS-CoV-2 IgG levels, regardless of the commercial immunoassay used. However, threshold levels of IgGs predicting high $\mathrm{NtAb}_{50}$ titers $(\geq 1 / 160)$ with high specificity $(93 \%)$ could be established for all immunoassays, although sensitivities were overall poor.

In the absence of a reference panel of sera with standard levels of $\mathrm{NtAb}$ antibodies, comparison across studies addressing the above issue is not straightforward, as the biological characteristics of the neutralization assay, the timing of sera collection, and the clinical severity of COVID-19 patients differ notably between them and may explain certain discrepancies. Namely, Weidner et al. [12] reported a strong correlation between IgG levels measured by the LIAISON SARSCoV-2 S1/S2 IgG and NtAb ${ }_{50}$ titers quantified by a wild-type SARS-CoV-2 assay (rho $=0.75$ versus rho $=0.59$ in the current study) in sera from convalescent COVID-19 patients. The degree of correlation reported by Muecksh et al. [20] in a comparable population using an HIV pseudotyped platform was even higher $($ rho $=0.82)$. Likewise, GeurtsvanKessel et al. [13] found a strong correlation $(r h o=0.75)$ using a live SARS$\mathrm{CoV}-2$ microneutralization assay and sera from a mixed patient population in terms of COVID-19 severity. Despite the abovehighlighted differences across studies, our correlation data agree with those of Weidner et al. [12] and GeurtsvanKessel et al. [13] for the Euroimmun IgG assay (rho 0.75 and 0.76, respectively, versus 0.73 herein) and those of Criscuolo et al. [15] who reported a low correlation between IgG levels measured by the LIAISON SARS-CoV-2 S1/S2 IgG and NtAb ${ }_{50}$ titers quantified by using a live SARS-CoV-2 platform in sera obtained within 15 days after the onset of symptoms in a small cohort of COVID-19 hospitalized patients. Moreover, Bonelli et al. [18] found that the probability of having $\mathrm{NtAb}_{50}$ titers $>1$ / 
Fig. 3 Kinetics patterns of serum $\mathrm{NtAb}_{50}$ titers quantitated by a SARS-CoV-2-S pseudotyped virus neutralization assay and SARS-CoV-2 IgG levels measured by commercial immunoassays in two representative patients displaying concordant (upper panels) or discordant (lower panels) kinetics a
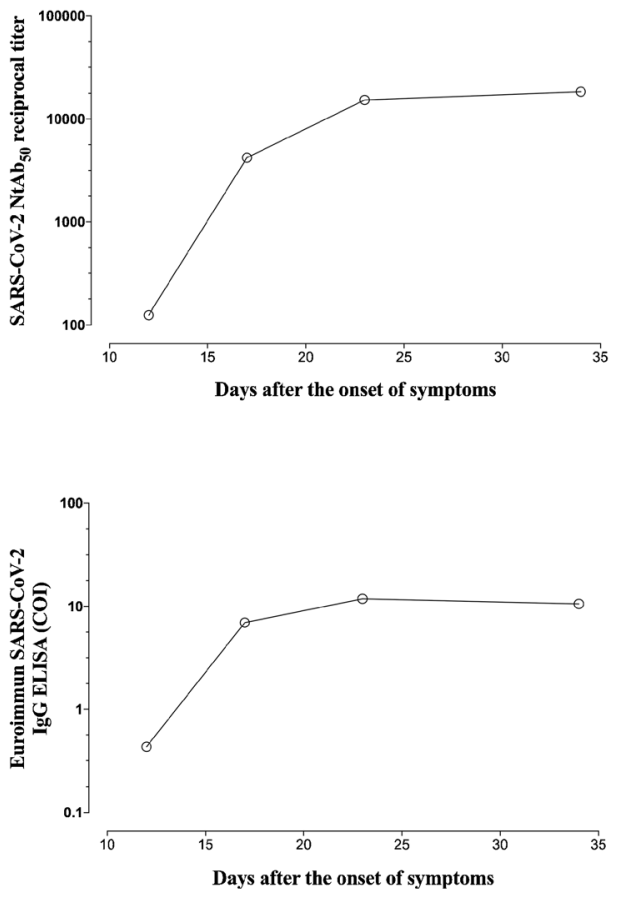

b
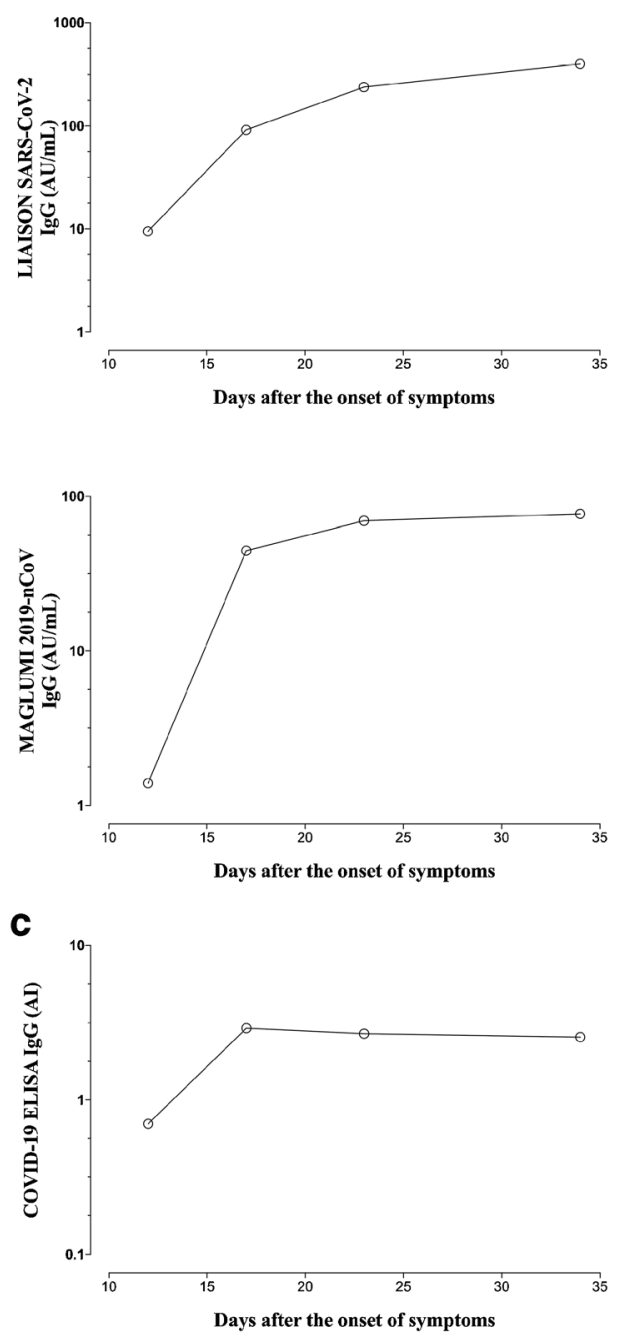
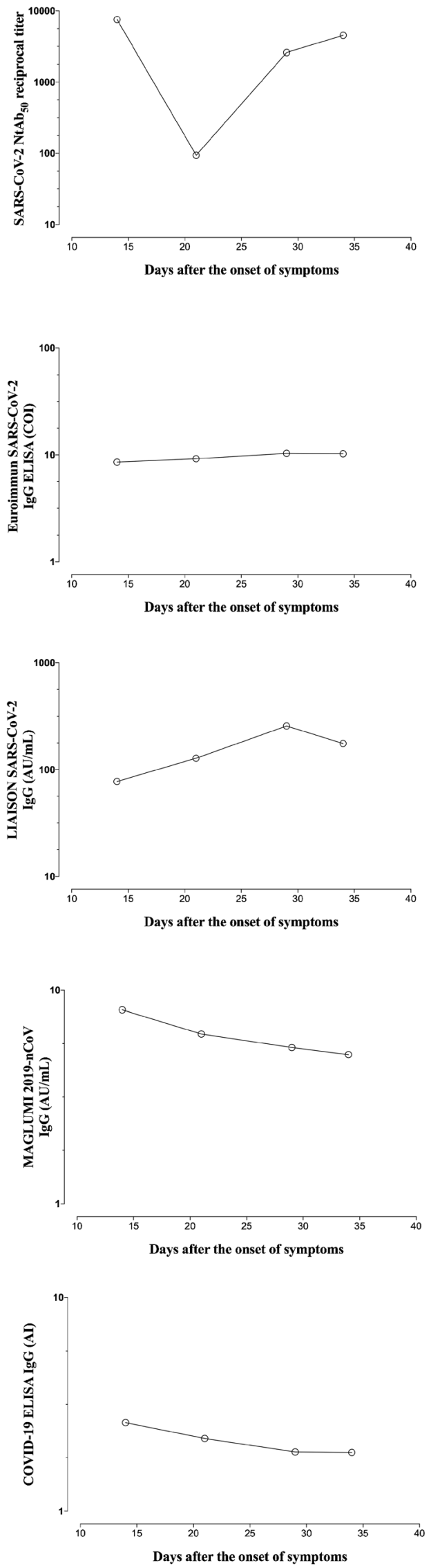
160 , as determined by a SARS-CoV-2 wild-type assay, was $92 \%$ when LIAISON SARS-CoV-2 S1/S2 IgG levels were > $80 \mathrm{AU} / \mathrm{mL}$ ( $90 \mathrm{AU} / \mathrm{mL}$ in the current study for a positive predictive value of 98\%). Also, in line with a previous report [20], the trajectory of $\mathrm{NtAb}_{50}$ titers could not be predicted by assessing SARS-CoV-2 IgG levels when measured by commercial immunoassays.

The current study has several limitations that deserve comment. First, due to small sample size, further studies are warranted to confirm our findings. Second, our conclusions strictly apply to COVID-19 hospitalized patients. Whether or not these can be extrapolated to asymptomatic or mildly symptomatic individuals not requiring hospitalization needs to be proven.

In summary, our data indicate that the reliability SARS$\mathrm{CoV}-2 \mathrm{IgG}$ commercial immunoassays targeting the $\mathrm{S}$ protein to infer neutralizing activity against this protein in sera from hospitalized COVID-19 patients varies widely across tests, this being better for assays targeting exclusively the $\mathrm{S}$ protein than for those detecting antibodies to the $\mathrm{S}$ and $\mathrm{N}$ proteins in combination, and depends upon the time of sera collection after the onset of symptoms.

Acknowledgments The authors would like to thank Gert Zimmer (Institute of Virology and Immunology, Mittelhäusern/Switzerland), Stefan Pöhlmann, and Markus Hoffmann (both German Primate Center, Infection Biology Unit, Goettingen/Germany) for providing the reagents required for the generation of pseudotyped VSV system. Eliseo Albert holds a Río Hortega research contract from the Carlos III Health Institute (Ref. CM18/00221). Ron Geller holds a Ramón y Cajal fellowship from the Spanish Ministry of Economy and Competitiveness (RYC-201517517).

Authors' contribution AV: methodology, analysis of data, validation, review, and editing; IT: formal analysis, review, and editing; VL: methodology and investigation; CFG: methodology and investigation; EA: resources, project administration, review, and editing; RG-R: methodology, investigation, validation, funding acquisition, review, and editing; MJA: methodology, analysis of data, validation, review, and editing; JB: supervision, review, and editing; JRD: conceptualization, supervision, funding acquisition, review, and editing; RG: methodology, investigation, validation, funding acquisition, review, and editing; DN: conceptualization, supervision, writing the original draft, review, and editing.

Funding This work was supported by Valencian Government grant IDIFEDER/2018/056 to JRD and Covid_19-SCI to RG.

\section{Compliance with ethical standards}

Conflict of interest The authors declare that they have no conflict of interest.

Ethical statement The current study was approved by the Research Ethics Committee of Hospital Clínico Universitario INCLIVA (March, 2020).

Informed consent Not applicable (as discussed with the institutional medical Ethical committee).

\section{References}

1. Zhou F, Yu T, Du R, Fan G, Liu Y, Liu Z, Xiang J, Wang Y, Song B, Gu X, Guan L, Wei Y, Li H, Wu X, Xu J, Tu S, Zhang Y, Chen H, Cao B (2020) Clinical course and risk factors for mortality of adult inpatients with COVID-19 in Wuhan, China: a retrospective cohort study. Lancet 395:1054-1062

2. Guan W-J, Ni Z-Y, Hu Y, Liang WH, Ou CQ, He JX, Liu L, Shan H, Lei CL, Hui DSC, Du B, Li LJ, Zeng G, Yuen KY, Chen RC, Tang CL, Wang T, Chen PY, Xiang J, Li SY, Wang JL, Liang ZJ, Peng YX, Wei L, Liu Y, Hu YH, Peng P, Wang JM, Liu JY, Chen Z, Li G, Zheng ZJ, Qiu SQ, Luo J, Ye CJ, Zhu SY, Zhong NS (2020) Clinical characteristics of coronavirus disease 2019 in China. New Engl J Med 382:1708-1720

3. Moore JP, Klasse PJ (2020) SARS-CoV-2 vaccines: 'Warp Speed' needs mind melds not warped minds. J Virol. https://doi.org/10. 1128/JVI.01083-20

4. Zohar T, Alter G (2020) Dissecting antibody-mediated protection against SARS-CoV-2. Nat Rev Immunol 20:392-394

5. Zost SJ, Gilchuk P, Case JB, Binshtein E, Chen RE, Nkolola JP, Schäfer A, Reidy JX, Trivette A, Nargi RS, Sutton RE, Suryadevara N, Martinez DR, Williamson LE, Chen EC, Jones T, Day S, Myers L, Hassan AO, Kafai NM, Winkler ES, Fox JM, Shrihari S, Mueller BK, Meiler J, Chandrashekar A, Mercado NB, Steinhardt JJ, Ren K, Loo YM, Kallewaard NL, McCune BT, Keeler SP, Holtzman MJ, Barouch DH, Gralinski LE, Baric RS, Thackray LB, Diamond MS, Carnahan RH, Crowe JE Jr (2020) Potently neutralizing and protective human antibodies against SARS-CoV-2. Nature. https:// doi.org/10.1038/s41586-020-2548-6

6. Shen C, Wang Z, Zhao F, Ang Y, Li J, Yuan J, Wang F, Li D, Yang M, Xing L, Wei J, Xiao H, Yang Y, Qu J, Qing L, Chen L, Xu Z, Peng L, Li Y, Zheng H, Chen F, Huang K, Jiang Y, Liu D, Zhang Z, Liu Y, Liu L (2020) Treatment of 5 critically ill patients with COVID-19 with convalescent plasma. JAMA 323:1582-1589

7. Xia X, Li K, Wu L, Wang Z, Zhu M, Huang B, Li J, Wang Z, Wu W, Wu M, Li W, Li L, Cai Y, Bosco B, Zhong A, Liu X, Lv T, Gan Z, Chen G, Pan Y, Liu C, Zhang K, Xu X, Wang C, Wang Q (2020) Improved clinical symptoms and mortality on severe/critical COVID-19 patients utilizing convalescent plasma transfusion. Blood. https://doi.org/10.1182/blood.2020007079

8. Wang Y, Zhang L, Sang L, Ye F, Ruan S, Zhong B, Song T, Alshukairi AN, Chen R, Zhang Z, Gan M, Zhu A, Huang Y, Luo L, Mok CKP, Al Gethamy MM, Tan H, Li Z, Huang X, Li F, Sun J, Zhang Y, Wen L, Li Y, Chen Z, Zhuang Z, Zhuo J, Chen C, Kuang L, Wang J, Lv H, Jiang Y, Li M, Lin Y, Deng Y, Tang L, Liang J, Huang J, Perlman S, Zhong N, Zhao J, Malik Peiris JS, Li Y, Zhao J (2020) Kinetics of viral load and antibody response in relation to COVID-19 severity. J Clin Invest 7:138759

9. Ni L, Ye F, Cheng M-L, Deng YQ, Zhao H, Wei P, Ge J, Gou M, Li X, Sun L, Cao T, Wang P, Zhou C, Zhang R, Liang P, Guo H, Wang X, Qin CF, Chen F, Dong C (2020) Detection of SARSCoV-2-specific humoral and cellular immunity in COVID-19 convalescent individuals. Immunity. https://doi.org/10.1016/j.immuni. 2020.04.023

10. To KK, Tsang OT, Leung WS, Am AR, Wu TC, Lung DC, Yip CC, Cai JP, Chan JM, Chik TS, Lau DP, Choi CY, Chen LL, Chan WM, Chan KH, Ip JD, Ng AC, Poon RW, Luo CT, Cheng VC, Chan JF, Hung IF, Chen Z, Chen H, Yuen KY (2020) Temporal profiles of viral load in posterior oropharyngeal saliva samples and serum antibody responses during infection by SARS-CoV-2: an observational cohort study. Lancet Infect Dis 20:565-574

11. Foundation for Innovative New Diagnostics. SARS-COV-2 diagnostic pipeline.www.finddx.org/covid-19/pipeline/?section= immunoassays\#diag_tab. Accessed July 20, 2020 
12. Weidner L, Gänsdorfer S, Unterweger S, Weseslindtner L, Drexler C, Farcet M, Witt V, Schistal E, Schlenke P, Kreil TR, Jungbauer C (2020) Quantification of SARS-CoV-2 antibodies with eight commercially available immunoassays. J Clin Virol 129:104540. https://doi.org/10.1016/j.jcv.2020.104540

13. GeurtsvanKessel CH, Okba NMA, Igloi Z, Bogers S, Embregts CWE, Laksono BM, Leijten L, Rokx C, Rijnders B, RahamatLangendoen J, van den Akker JPC, van Kampen JJA, van der Eijk AA, van Binnendijk RS, Haagmans B, Koopmans M (2020) An evaluation of COVID-19 serological assays informs future diagnostics and exposure assessment. Nat Commun 11:3436

14. Ng D, Goldgof G, Shy B, Levine A, Balcerek J, Bapat SP, Prostko J, Rodgers M, Coller K, Pearce S, Franz S, Du L, Stone M, Pillai S, Sotomayor-Gonzalez A, Servellita V, Sanchez-San Martin C, Granados A, Glasner DR, Han LM, Truong K, Akagi N, Nguyen DN, Neumann N, Qazi D, Hsu E, Gu W, Santos YA, Custer B, Green V, Williamson P, Hills NK, Lu CM, Whitman JD, Stramer S, Wang C, Reyes K, Hakim J, Sujishi K, Alazzeh F, Pharm L, Oon CY, Miller S, Kurtz T, Hackett J, Simmons G, Busch MP, Chiu CY (2020) SARS-CoV-2 seroprevalence and neutralizing activity in donor and patient blood from the San Francisco Bay Area. medRxiv preprint. https://doi.org/10.1101/2020.05.19.20107482

15. Criscuolo E, Diotti RA, Strollo M, Rolla S, Ambrosi A, Locatelli M (2020) Poor correlation between antibody titers and neutralizing activity in sera from SARS-CoV-2 infected subjects. medRxiv. https://doi.org/10.1101/2020.07.10.20150375

16. Jääskeläinen AJ, Kuivanen S, Kekäläinen E, Ahava MJ, Loginov R, Kallio-Kokko H, Vapalahti O, Jarva H, Kurkela S, Lappalainen M (2020) Performance of six SARS-CoV-2 immunoassays in comparison with microneutralisation. J Clin Virol 129:104512

17. Suhandynata RT, Hoffman MA, Huang D, Tran JT, Kelner MJ, Reed SL (2020) Commercial serology assays predict neutralization activity against SARS-CoV-2. medRxiv. https://doi.org/10.1101/ 2020.07.10.20150946

18. Bonelli F, Sarasini A, Zierold C, Calleri M, Bonetti A, Vismara C, Blocki FA, Pallavicini L, Chinali A, Campisi D, Percivalle E, DiNapoli AP, Perno CF, Baldanti F (2020) Clinical and analytical performance of an automated serological test that identifies S1/S2 neutralizing IgG in COVID-19 patients semiquantitatively. J Clin Microbiol. https://doi.org/10.1128/JCM.01224-20

19. Kohmer N, Westhaus S, Rühl C, Ciesek S, Rabenau HF (2020) Brief clinical evaluation of six high-throughput SARS-CoV-2 IgG antibody assays. J Clin Virol 129:104480. https://doi.org/10.1016/j. jcv.2020.104480

20. Muecksch F, Wise H, Batchelor B, Squires M, Semple E, Richardson C, McGuire J, Cleary S, Furrie E, Greig N, Hay G, Templeton K, Lorenzi JCC, Hatziioannou T, Jenks SJ, Bieniasz P
(2020) Longitudinal analysis of clinical serology assay performance and neutralising antibody levels in COVID19 convalescents. medRxiv. https://doi.org/10.1101/2020.08.05.20169128

21. Barnes CO, West AP Jr, Huey-Tubman KE, Hoffmann MAG, Sharaf NG, Hoffman PR, Hägglöf T, Hurley A, Millard KG, Weisblum Y, Schmidt F, Hatziioannou T, Bieniasz PD, Caskey M, Robbiani DF, Nussenzweig MC, Bjorkman PJ (2020) Structures of human antibodies bound to SARS-CoV-2 spike reveal common epitopes and recurrent features of antibodies. Cell S00928674(20):30757-30751

22. Rogers TF, Zhao F, Huang D, Beutler N, Burns A, He WT, Limbo O, Smith C, Song G, Woehl J, Yang L, Abbott RK, Callaghan S, Garcia E, Hurtado J, Parren M, Peng L, Ramirez S, Ricketts J, Ricciardi MJ, Rawlings SA, Wu NC, Yuan M, Smith DM, Nemazee D, Teijaro JR, Voss JE, Wilson IA, Andrabi R, Briney B, Landais E, Sok D, Jardine JG, Burton DR (2020) Isolation of potent SARS-CoV-2 neutralizing antibodies and protection from disease in a small animal model science. Science:eabc7520. https://doi.org/10.1126/science.abc7520

23. Giménez E, Albert E, Torres I, Remigia MJ, Alcaraz MJ, Galindo MJ, Blasco ML, Solano C, Forner MJ, Redón J, Signes-Costa J, Navarro D (2020) SARS-CoV-2-reactive interferon- $\gamma$-producing $\mathrm{CD} 8+\mathrm{T}$ cells in patients hospitalized with coronavirus disease 2019. J Med Virol. https://doi.org/10.1002/jmv.26213

24. Gozalbo-Rovira R, Gimenez E, Latorre V, Frances-Gomez C, Albert E, Buesa J, Marina A, Blasco ML, Signes-Costa J, Rodriguez-Diaz J, Geller R, Navarro D (2020) SARS-CoV-2 antibodies, serum inflammatory biomarkers and clinical severity of hospitalized COVID-19 patients. medRxiv. https://doi.org/10. $1101 / 2020.07 .22 .20159673$

25. Recommendations for investigational COVID-19 convalescent plasma. https://www.fda.gov/vaccines-blood-biologics/ investigational-new-drug-ind-or-device-exemption-ide-processcber/recommendations-investigational-covid-19-convalescentplasma. Accessed July 5, 2020

26. Schmidt F, Weisblum Y, Muecksch F, Hoffmann HH, Michailidis E, Lorenzi JCC, Mendoza P, Rutkowska M, Bednarski E, Gaebler C, Agudelo M, Cho A, Wang Z, Gazumyan A, Cipolla M, Caskey M, Robbiani DF, Nussenzweig MC, Rice CM, Hatziioannou T, Bieniasz PD (2020) Measuring SARS-CoV-2 neutralizing antibody activity using pseudotyped and chimeric viruses. J Exp Med 217(11):e20201181

Publisher's note Springer Nature remains neutral with regard to jurisdictional claims in published maps and institutional affiliations. 